\title{
Coulisses
}

Revue de théâtre

19 | Hiver 1999

Varia

\section{Le Cœur d'amour épris}

Création 1998 du Centre d'Animation du Haut-Doubs, scène

départementale du Doubs - Conception et mise en scène : Pierre Louis Nouveau Théâtre, CDN de Besançon - Novembre 1998

\section{Stéphane Besson}

\section{OpenEdition}

\section{Journals}

Édition électronique

URL : https://journals.openedition.org/coulisses/5445

DOI : $10.4000 /$ coulisses. 5445

ISSN : 2546-9460

\section{Éditeur}

Presses universitaires de Franche-Comté

\section{Édition imprimée}

Date de publication : 1 janvier 1999

Pagination : 21

ISBN : 2-913322-09-3

ISSN : $1150-594 \mathrm{X}$

Référence électronique

Stéphane Besson, « Le Cœur d'amour épris », Coulisses [En ligne], 19 | Hiver 1999, mis en ligne le 18 octobre 2019, consulté le 12 janvier 2022. URL : http://journals.openedition.org/coulisses/5445 ; DOI : https://doi.org/10.4000/coulisses.5445

Ce document a été généré automatiquement le 12 janvier 2022.

Coulisses 


\section{Le Cœur d'amour épris}

Création 1998 du Centre d'Animation du Haut-Doubs, scène départementale du Doubs - Conception et mise en scène : Pierre Louis ${ }^{1}$ Nouveau Théâtre, CDN de Besançon - Novembre 1998

\section{Stéphane Besson}

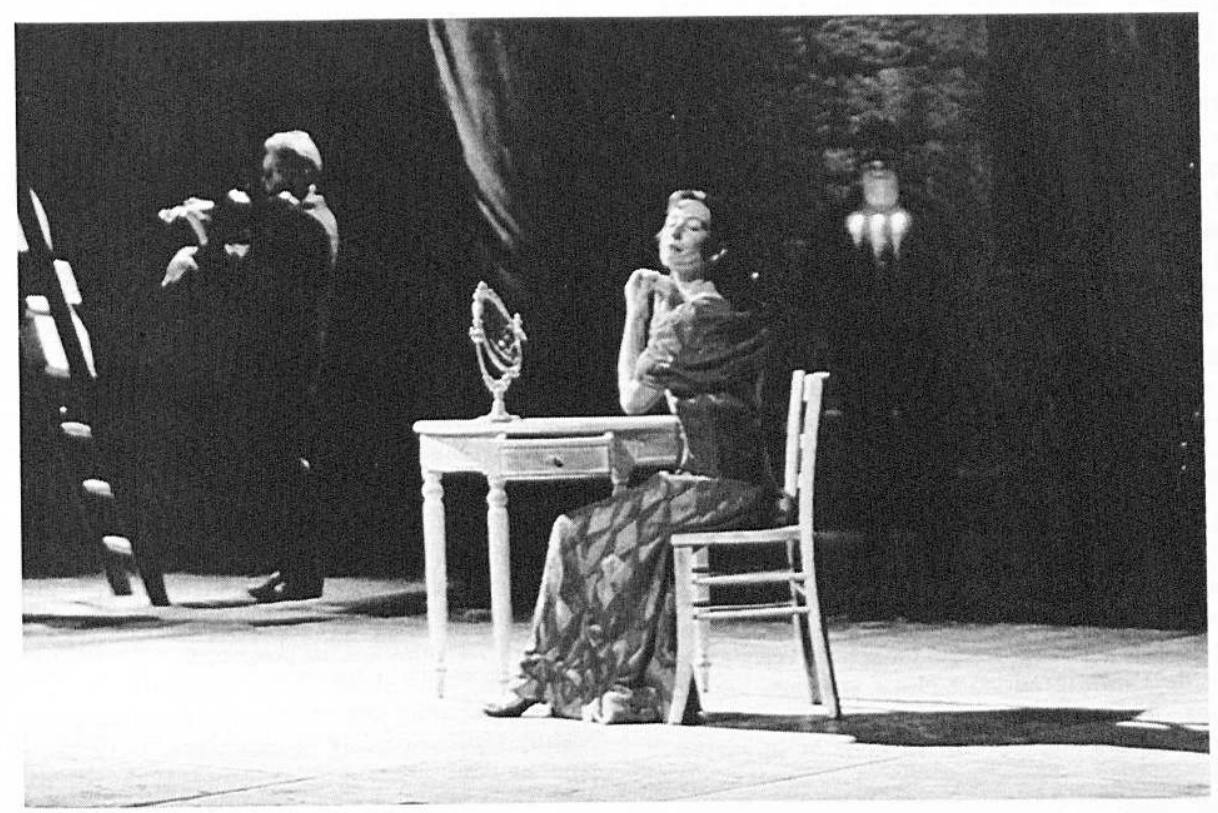

Photo CAHD

1 Ils ont vingt, trente ou cinquante ans. Ils sont comédiens, danseurs, chanteurs, musiciens, bref: artistes. Ils mettent en scène les personnages de La mouette de Tchekhov ou de Bérénice de Racine, la musique de Bach, de Mozart, de Bizet, les chansons de Piaf, Trenet, Claude François, Rita Mitsouko. Tour à tour, ils passent de la fanfare au tango, d'une ambiance jazzy à la solennité d'un quatuor à cordes. Ils aspirent un instant la gravité, et la joie la séquence d'après. Et ils aiment! Ils nous montrent 
l'amour sous ses multiples visages : amour tragique, tendre, sensuel, conjugal, poète, désespéré, passionné...

2 Une énumération, un catalogue : c'est bien ainsi que se présente ce "montage théâtral et musical» de Pierre Louis, où théâtre, danse et musique se marient harmonieusement, où l'amour de l'art et l'amour de l'autre s'unissent pour le meilleur. Le prétexte (les artistes sortent d'une audition) est vite oublié. Peu nous importe qui ils sont, d'où ils viennent, quelles ambitions ils nourrissent. Ils sont présents et heureux, voilà l'essentiel. Heureux d'être sur scène, face à nous et face à eux-mêmes, heureux de chanter, de jouer la comédie, de danser, heureux de vivre!

Loin des machineries-machinations, des combinations philosophico-narratives du spectacle intello, loin des artifices scéniques habituels, ce Cœur d'amour épris se vit dans l'instant et dans la présence, dans l'évidence et le premier degré, «pour libérer son cœur, simplement. $»^{2}$

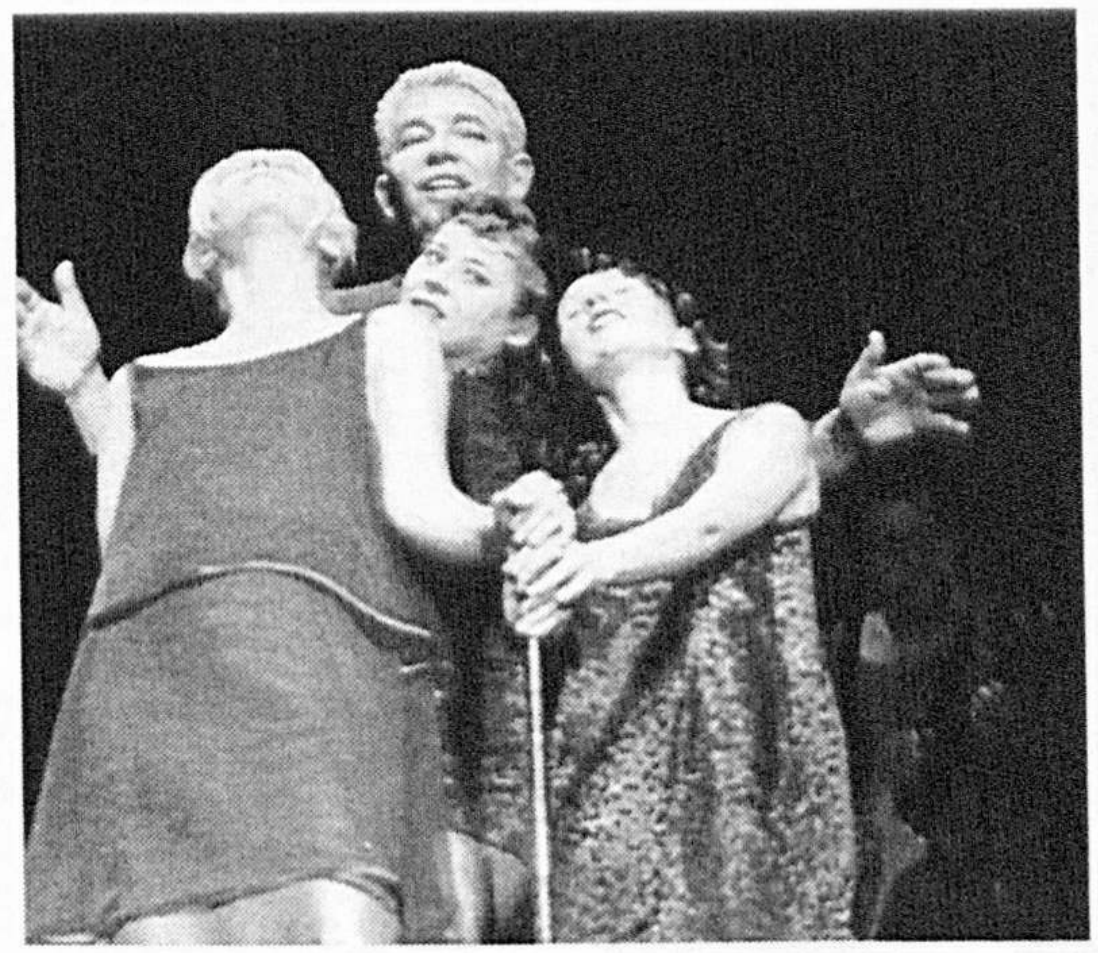

Photo CAHD

\section{NOTES}

1. Directeur du CAHD ; voir Coulisses $n^{\circ} 10$. Sur quelques-unes des précédentes créations de Pierre Louis, voir Coulisses $n^{\circ} 9$, p. $22 ; n^{\circ} 15$, p. 25 et p. 33.

2. Tchekhov, La Mouette, acte IV. 


\section{AUTEURS}

STÉPHANE BESSON

TUFC 